EGU21-5424

https://doi.org/10.5194/egusphere-egu21-5424

EGU General Assembly 2021

(C) Author(s) 2021. This work is distributed under

the Creative Commons Attribution 4.0 License.

\title{
Pseudotachylyte veins in accretionary complexes: melt or mechanical wear?
}

Benjamin Moris-Muttoni, Hugues Raimbourg, Romain Augier, Rémi Champallier, Emmanuel Le Trong, and Yan Chen

Institut des Sciences de la Terre d'Orléans, Université d'Orléans, CNRS, BRGM, ISTO, UMR 7327, F-45071 Orléans, France. (benjamin.moris-muttoni@cnrs-orleans.fr)

Whether seismic rupture propagates over large distances to generate mega-earthquakes or on the contrary slows down quickly, is heavily dependent on the slip processes operating within the fault core, such as frictional melting or intense grain-size reduction and amorphization. The record, in fossil fault zones, of seismic slip, consists in many instances in Black Faults Rocks (BFR), that consists in a generally thin dark and aphanitic veins similar to volcanic glasses, which cross-cuts sharply a weakly foliated tectonic mélange, and have been interpreted as resulting from quenching of a melt (i.e. pseudotachylytes). Such interpretation has nevertheless been questioned because identical (micro- and nano-) textures have been observed on intensely comminuted natural fault rocks and on slow creep experiments on crustal rocks.

In this study, we report a new dataset of high spatial-resolution Raman Spectroscopy of Carbonaceous Materials (RSCM) profiles across natural BFR from two accretionary complexes. RSCM is sensitive to both temperature and deformation. We have carried out analyses on Okitsu and Nobeoka BFR from the Shimanto Belt and Kodiak BFR from the Kodiak Accretionary Complex to discriminate the slip weakening process. The Raman Intensity Ratio (i.e. R1 in Beyssac et al., 2002) and the Area ratio (RA1 in Lahfid et al., 2010) show a drastic and discontinuous stepped increase along profiles across the BFR, revealing a higher crystallinity. Moreover, in spite of scattering, highest values have been measured on the rim between the BFR and the host-rock. Fluidization structures, interpreted as injection veins, show similar values to the ones in the host rock. Additionally, using an experimentally calibrated kinetics 1D modelling of Intensity ratio evolution with temperature, we compared the natural Raman spectroscopy profiles to different scenarios of temperature increase during seismic slip. In the three examples of BFR from accretionary complexes interpreted as natural pseudotachylytes, RSCM profiles are not consistent with a molten origin and must reflect mechanical wear during deformation.

Consequently, these results bear major consequences on the dynamics of faulting in accretionary complexes, as the slip-weakening processes that occur during seismic slip rely on extreme grainsize reduction and fluidization rather than melting. 